EL

24,2

190

\title{
How researchers are using the OPAC of the Spanish Council for Scientific Research Library Network
}

\author{
Virginia Ortiz-Repiso \\ Department of Librarianship and Information Science, \\ University Carlos III de Madrid, Madrid, Spain \\ Virginia Bazán \\ Document Centre of Televisión Española, Madrid, Spain, and \\ Agnès Ponsati and Mario Cottereau \\ Library Co-ordination Unit, Spanish Council for Scientific Research, \\ Madrid, Spain
}

\begin{abstract}
Purpose - The importance of online public access catalogues (OPACs) has changed in recent years, mainly due to the large number of electronic resources now available. The aim of this study is to learn about and evaluate the use made by researchers of the OPAC of the library network of the Spanish Council for Scientific Research, the largest research institution in Spain.

Design/methodology/approach - To this end a questionnaire was drafted with questions pertaining both to the system and to the users themselves. The information gathered was supplemented by data obtained from the transaction logs.

Findings - The results have revealed the use made of the OPAC and the characteristics of the searches performed. Users are still confronted by classic problems of information seeking: information overload, errors in subject searching, and the predominant use of the system's simpler options. The results show that the OPAC is broadly used by end-users not only for obtaining printed material, but also for connecting to the electronic resources subscribed to by the library.
\end{abstract}

Originality/value - The OPAC should continue to occupy an important position in the library's overall information environment, interacting with other information systems.

Keywords Online catalogues, User studies, Research organizations, Spain

Paper type Case study

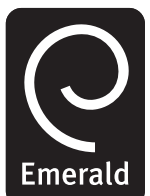

The Electronic Library Vol. 24 No. 2, 2006 pp. $190-211$

(C) Emerald Group Publishing Limited 0264-0473

DOI $10.1108 / 02640470610660378$

\section{Introduction}

The card catalogue and, subsequently, the online public access catalogue (OPAC) have historically represented the central element of most libraries. Traditionally, the catalogue had been referred to as the "heart of the system" in the broadest sense: the core component of the library as an organization and the centre of the automated system managing both the collection and the services relating to it. From their appearance in the middle of the 1970s, OPACs have progressed through different generations and towards the end of the 1990s they began taking on the form that predominates today: the web interface. These catalogues constitute an advance over their predecessors, especially in regards to remote access by users and to the potential 
for integrating documents and resources of different types into a single interface. However, their functionality has not kept abreast of the changes.

In the last two decades of the twentieth century, OPACs were the subject of important and extensive studies, as witnessed by the large number of published works (Large and Beheshti, 1997). Nevertheless, interest in them has declined in recent years, mainly due to the appearance of a new protagonist on the library scene: the online electronic resource. The appearance of these new resources has led to other, more novel tools and products taking precedent as a research subject and, furthermore, has influenced patrons' use of OPACs and their expectations of them (Yu and Young, 2004).

During the early years of the OPAC evolution, no one challenged the value of the information they contained. Today, by contrast, the situation has changed and frequently their worth is questioned (Delsey, 2001). Currently there is a move from a world based on print documents to another in which much information is digital and found on networks. Libraries are revising their service strategies and, as a consequence, are reviewing their catalogues and the role that these play in the overall offering of information services.

Two central aspects of online public access catalogues are integration and diversification. Integration refers to the fact that the catalogue contains not only documents that the library owns, but also others to which it provides access: e-books, e-journals, databases, free web resources and so forth (Delsey, 2001). Diversification refers to the fact that these resources can be reached, moreover, via routes and systems other than the OPAC. On the one hand, this enhances searching possibilities. But on the other, the panorama is more complicated for the end user who must use a variety of retrieval tools: for instance, the local OPAC or those of other libraries, a bibliographic database subscribed to by the library, a platform of e-journals, or a web search engine (Webster, 2004).

Diversification is, at times, difficult to understand since there are many services vying to mine the same market and offering similar products for retrieving information. The generic name given to this sector is the "content industry". Why would a library user go into the OPAC in order to locate an article in an e-journal, instead of going directly to the distributor's server? What function does the OPAC currently serve as a retrieval tool in the library? The answers to these questions are related to use, OPAC features, and the level of end user satisfaction.

The primary goal of this study was to analyze, evaluate, and determine the end users' opinions and usage of the new version of the OPAC at the Library Network of Spanish Council for Scientific Research (CSIC). The users included both those that belong to the institution as well as others external to it. Two more specific objectives stem from this main goal: first, to identify the different groups of users as well as their habits and information needs, while at the same time discovering potential user groups that do not use the catalogue and their reasons for not doing so. Second, to define users' searching habits in order to determine how the system benefits them and to understand the most frequently recurring problems encountered in searching and how solutions are sought. At the same time, the study hoped to measure the ease with which users deal with those concepts and terms specific to the library sector that are frequently employed in OPACs and other retrieval systems.

This work will lead to an understanding - from the point of view of the end users of the role that the OPAC currently plays among the information retrieval tools being 
EL

24,2

192

offered by libraries. In addition, it will provide insights into whether the mechanical and conceptual problems that have been cited over the years in numerous studies about online public access catalogues still persist, especially those referring to subject access (Borgman, 1986, 1996; Larson, 1991a, b; Hildreth, 1985; Cochrane and Markey, 1983; Hunter, 1991). Finally, this study will help to identify what position the OPAC should occupy in the library's overall information environment and what its interaction with other information systems should be.

Before moving to the methodology and the analysis of the data, a description of the types of libraries involved in this study is provided below.

\section{The Library Network of the CSIC}

The Library Network of the CSIC is a public research organization that is multisectorial and multidisciplinary. It falls under the Spanish Ministry of Education and Science, with a presence throughout the country. It maintains collaborative relations with the public sector (national, autonomic, and local) and with other research institutions (universities, public and private research bodies). It also has ties with other social and economic agents, both national and foreign, to which CSIC offers its research capability, its human and material resources for developing research projects, and technical and scientific support and advice.

The CSIC is made up of 100 institutes, each of which has a specialized library to support research. These libraries are organized within the CSIC's Library Network, consisting of 100 libraries distributed over 21 cities within 10 Autonomous Communities. Of these, 17 belong to centres under mixed arrangements with universities. The libraries represent one of the most important assets of the scientific information system in Spain: a highly specialized bibliographic patrimony consisting of more than 1,400,000 monographs and 44,408 serial titles corresponding to 76,157 journal runs, as well as other types of bibliographic material such as maps, photographs, manuscripts and so forth.

The subject distribution of these libraries coincides with CSIC's lines of research: biology and biomedicine, food technology, materials technology, physical technologies, chemical technologies, agricultural sciences, humanities and social sciences, computer and information science, and natural resources.

The Network uses the library management system, Aleph 500, to handle its services and catalogues and to generate one of the largest automated union catalogues of scientific information in Spain: CIRBIC (Automated Catalogues of CSIC's Library Network). In December 2003, a new version of this system -v.14.2 - was installed, introducing important changes to the web-based search interface that affected not only the design of the system but also its functionality. The two most significant changes resulting from this new version were the introduction of the Unicode character system for encoding bibliographic information and an entirely new web-based search interface affecting both appearance and functionality. This new interface represented a notable improvement in terms of speed and reliability of responses and also of ergonomics and ease of use for end users. This improvement was due in part to the new frameless screens and to the fact that the system runs on an Apache web server. Other enhancements introduced are focused on the user zone. A new user-oriented service in addition to those already existing (loan information, document requests, etc.) is the possibility of creating Selective Dissemination of Information (SDI) alerts - the 
periodic transmission of new records corresponding to a search profile - with information presented in a more comprehensive and accessible manner.

As of 2005 the OPAC contains 99 per cent of the previously automated monographic holdings and all the journals held, as well as a growing catalogue of maps, archives, authority records, and e-journals. The scholarly journal holdings are particularly important by virtue of their high numbers, their degree of specialization, the breadth of time coverage, and the important investment that they represent for the institution. In the final months of 2004, a dynamic link server - based on SFX - was installed and in April 2005 a portal for accessing information resources - using METALIB - became operative, representing a major advance in the process of creating CSIC's Virtual Library.

\section{Methodology}

In order to identify the level of user satisfaction with OPAC features and the problems that users had with CSIC's OPAC, a questionnaire was developed to address various issues relating both to the user and to the system itself, divided into six different sections:

(1) information concerning the user;

(2) general appraisal of the OPAC;

(3) search options;

(4) search results;

(5) presentation of results; and

(6) document access.

In order to meet the proposed objectives, the questions - both subjective and objective - were drafted using a simple language and style, avoiding the use of abbreviations and terms taken from technical library terminology in order to elicit as many responses as possible.

The main aim of the subjective questions was to gather information about the level of user satisfaction regarding specific system functions, the use made of specific features, or the ease of use of different search options. Objective questions were intended to contrast the users' own opinions with the system's actual performance by comparing user responses with the catalogue's own statistics.

A pilot test was run during the second week of April 2004, in which 12 Network libraries and approximately sixty users took part. Once their responses were received, appropriate changes were introduced and the final version was prepared in HTML and posted on the web page of CSIC's Library Network Information Server[1] as well as on the OPAC's search interface[2]. This second option allowed the questionnaire to be answered by many of the OPAC's external users and greatly facilitated the handling of the data. The HTML questionnaire was linked to a Common Gateway Interface (CGI) that gathered the user responses and sent them - coded and delimited by separators in a text format - to a specific e-mail address. Once the test period had ended, this information was exported to an Access database for processing. The final questionnaire was posted on CSIC's Library Network Server on May 2004 and remained available until 30 June 2004. 
EL

24,2

194

Figure 1.

Area of user specialization
Finally, the results obtained through the questionnaire were supplemented by data from the statistical analysis of transaction logs, carried out annually by CSIC's Unit of Library Co-ordination, the office responsible for managing the system and the catalogue. This is now a classic method used in OPAC research (Halcoussis et al., 2002).

\section{Data and discussion}

A total of 528 questionnaires were received, of which 387 (73 per cent) corresponded to internal CSIC users and 141 (27 per cent) were from persons external to the institution. The total number of potential users (researchers, personnel involved in training, and technical employees) of CSIC's Library Network is calculated at 5,724, and so the response index represents 6.76 per cent of internal users. The distribution of participants according to their area of specialization is shown in Figure 1. The participants are primarily researchers and the area most highly represented by the responses is Physical Science and Technology

Figure 2 shows the percentage of use of the catalogues and databases that CSIC's Library Network makes available to its users. This data coincides with the analysis of the transaction log that revealed 437,881 sessions during 2003. A session is defined here as the first access of a user to the catalogue. Therefore several searches carried out by the same user would be counted as a single session, unless more than 30 minutes transpired between searches, or if the user chose to initiate a new session. This number represents a 29 per cent increase over the previous year. The log file reveals a significant increase of searches in the e-journal catalogue (with 33,418 sessions, a 58 per cent increase over 2002), the authority catalogue (an increase of 57 per cent with 21,209 sessions), and the archives catalogue (with 10,699 sessions and a 17 per cent increase over 2002).

The profile of the CSIC user corresponds to a researcher in the area of sciences, with an average age above 41 and very accustomed to meeting his/her own information needs in the electronic environment, since 81.47 per cent regularly use other online catalogues and 96.02 per cent regularly use different information retrieval tools on the internet.

\section{Area of user specialization (528 responses)}

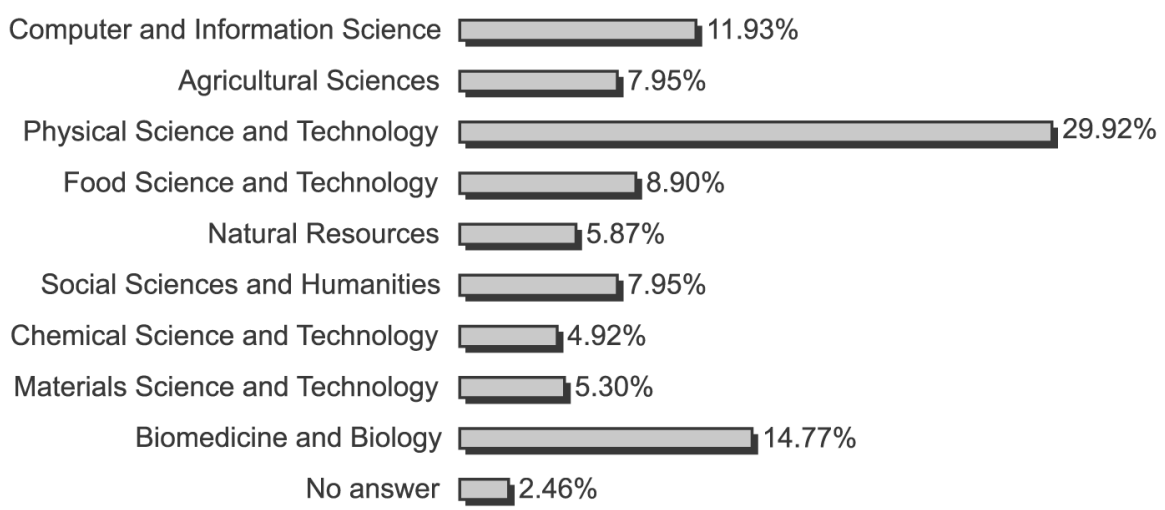




\section{Users of ... (528 responses)}

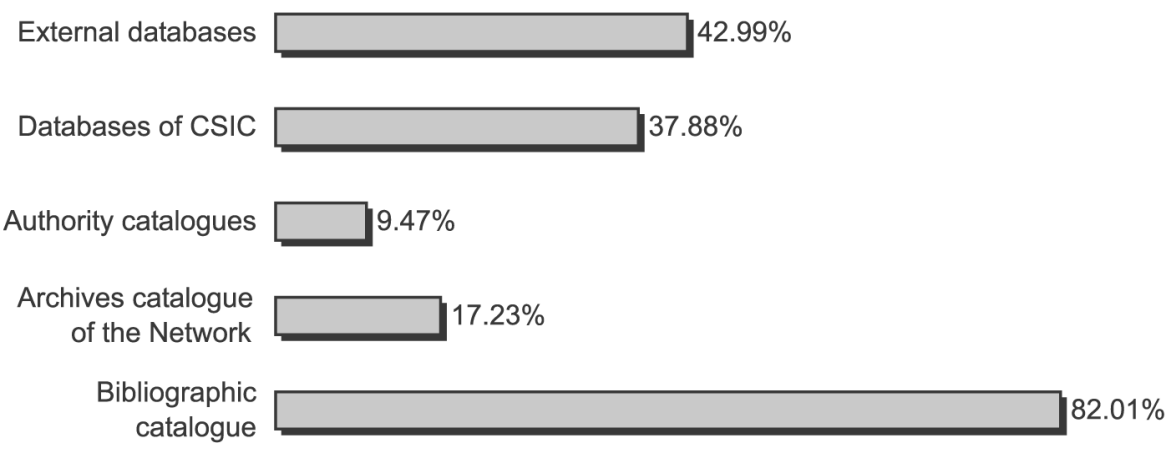

\section{Using the OPAC}

195

Figure 2. Users of ...

Of the users, 67.88 per cent connect to the catalogue between 1-20 times per month. The most frequent place used for accessing the catalogue (Figure 3) is from work (58.64 per cent) as opposed to 6.07 per cent of searches performed in the library itself. This finding clearly shows that the libraries are used increasingly more often via network connection.

The majority of users that participated in the study consider themselves to be average (47.73 per cent) whereas 13.83 per cent consider themselves to be expert, and 8.71 per cent identify themselves as novices. Only 10.42 per cent consider themselves to be occasional users (Figure 4).

As to the training users receive for accessing information via the OPAC, it is significant to note the high percentage claiming to have learned to use the catalogue intuitively. Those seeking help from librarians amount to 37.85 per cent and only a small fraction of users learned how to use the system through the online help screens or by reading brochures or manuals. There is no relation between the types of users and the manner by which they learned how to use the system because the majority did it

The catalogue is searched from ... (428 responses)

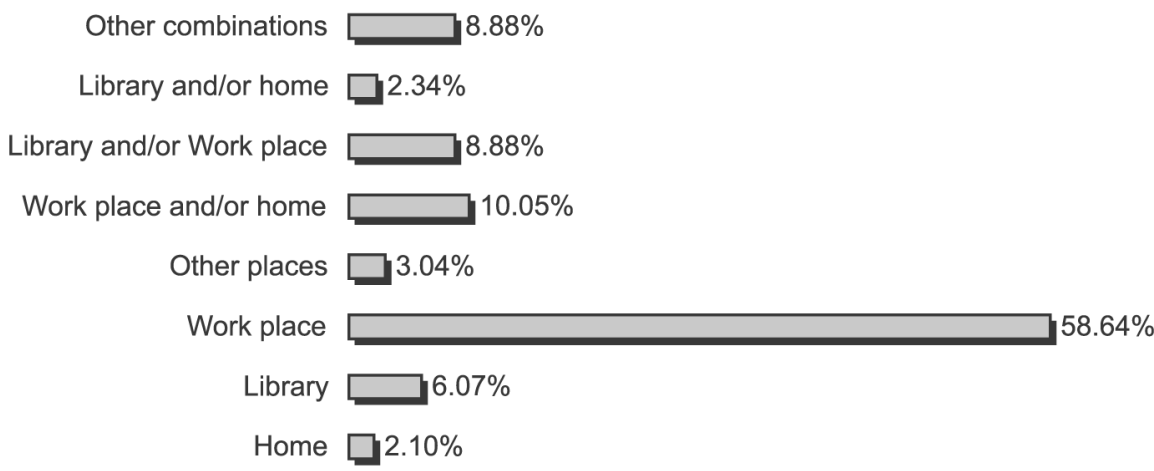

Figure 3. The catalogue is searched from ... 
Occasional user $\square 10.42 \%$ \\ 196}

Novice user

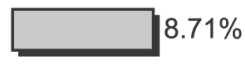

Average user

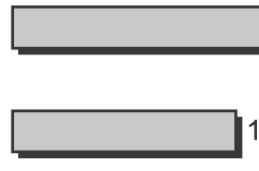

$13.83 \%$
Figure 4.

Types of users
Figure 5.

Users learn to use the OPAC ...
No answer

$19.32 \%$

intuitively, in the same way that they carry out searches on the web (Schwartz, 2002). To a lesser extent, they seek assistance from the librarian (Figure 5).

The users search the catalogue mainly for journals (54.44 per cent) as opposed to monographs (40.46 per cent) and other materials such as sound recordings, scores or CD-ROM. The search for journals is performed mainly in order to connect to the electronic version, as was detected through the transaction file.

Appraisal of the OPAC

The degree of user satisfaction with the catalogue can be gauged by different factors, among which are the interface, speed of system response, ease of use, and satisfaction with the obtained results.

Using a Lickert scale from 1 to 5 , in which 1 is poor and 5 , excellent, the catalogue obtained an average score of 3.58. Approximately 85 per cent of the users answering the questionnaire said they are satisfied or relatively satisfied with the catalogue in general terms (Figure 6). The users consider the improvements over the earlier version

\section{Users learn to use the OPAC ... \\ (428 responses)}

Intuitively

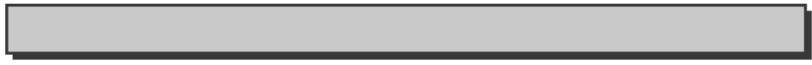

$77.10 \%$

\section{Librarians}

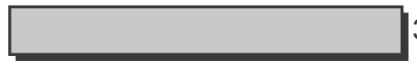

$37.85 \%$

Online help

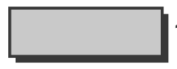

$14.72 \%$

Brochures and/or manuals $3.74 \%$ 
to be very positive, since somewhat more than 78 per cent feel that the OPAC had improved somewhat or quite a lot. Regarding the ease of use, 51.78 per cent of those answering the questionnaire consider it to be good or very good (Figure 7). Here it is worthwhile mentioning the important relationship between ease of use and satisfaction with the results obtained. Hildreth's research (2001) clearly demonstrates the positive correlation that exists between both factors, since users tend to consider a system to be easy to use when they feel the results of their queries to be adequate. The response time is considered to be good or excellent by 58.62 per cent of the users.

The clarity of the help screens and the knowledge that users have of the terminology used in bibliographic catalogues are important factors, since they can interfere with the search process. Figure 8 shows an overview of how users appraised the usefulness of help tools and the clarity of terms and abbreviations used in the catalogue. In terms of help tools, 50 per cent of the persons completing the questionnaire consider them to be of average usefulness and only 28.99 per cent as good or excellent. Borgman (1996) notes that that there are too few online help screens incorporated into OPACs and that the majority of them are too specific, frequently giving examples as how to enter personal names, subjects or titles, or how to use

\section{Degree of satisfaction with the OPAC (420 responses)}

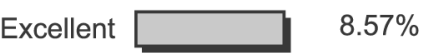

Good

Average

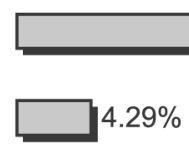

\section{Poor \\ $1.90 \%$ \\ Ease of using the OPAC \\ (421 responses) \\ Unsatisfactory $\square 4.29 \%$

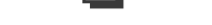

\begin{abstract}
Excellent
\end{abstract}

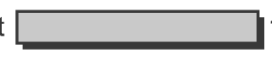

$11.16 \%$

Good

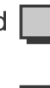

Average

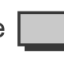

Unsatisfactory

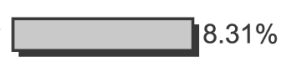

Poor

$3.56 \%$
$49.29 \%$

$35.95 \%$

\section{Using the OPAC}

197
Figure 6.

Degree of satisfaction with the OPAC
Figure 7. Ease of use of the OPAC 
EL

24,2

198

Figure 8.

Usefulness of help tools

\section{Usefulness of help tools \\ (376 responses)}

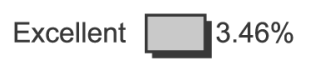

Good

$25.53 \%$

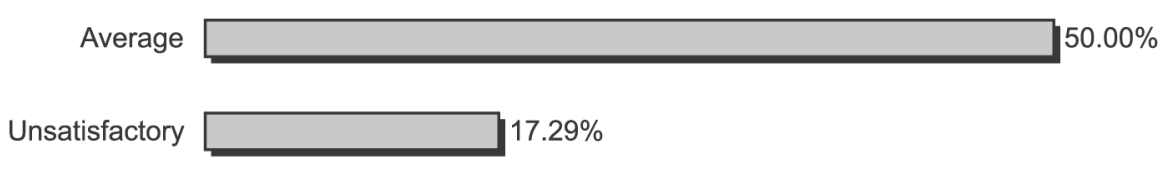

Poor $\square 3.72 \%$

Boolean operators. Until the design of intuitive systems requiring minimal user training becomes a reality, online catalogues would become easier to use if users could find help tools appropriate to their individual needs and learning capacity.

Bibliographic catalogues, as has been noted on many occasions, employ a terminology that is too highly technical and thus difficult for users to understand, as well as containing confusing error messages (Ortiz-Repiso and Moscoso, 1999). Nevertheless, it is surprising to see that approximately 70 per cent of CSIC's OPAC users consider both the terminology and the error messages to be good/average.

On the other hand, a more in-depth analysis of the users' understanding of these items sheds a different light on the issue. The best understood terms are ISBN/ISSN and Abbreviated title. This is logical since, as was noted above, the materials most often sought are journals. However, other terms such as Subject headings, Uniform title, or Imprint are much less understood. It is surprising to see that slightly more than half of the users are unaware of what "truncation" or "UDC" refers to (Figure 9).

\section{Search options}

CSIC's OPAC offers four types of searches: Basic - the default search- allowing retrieval based on words found throughout the record or in specific fields: Advanced, permitting searches by words and by using Boolean operators and delimiters (media, language, library, etc.); Expert, allowing retrieval through the use of Common Command Language commands; and Browsing indexes, allowing for retrieval on fields such as author, title, subject, series and so forth.

The option preferred by the users is the basic search (Figure 10), without there being noticeable differences between users that consider themselves to be average ( 63.10 per cent), occasional (69.09 per cent), or novice (65.22 per cent). However there was a lower percentage of expert users (only 36.99 per cent chose the basic search) due to their higher preference for the advanced search. The predominant preference for the basic search should be taken in consideration with a fundamental factor: the basic search option is the system default. Also, users tend to be unaware of the more sophisticated features of the system (Peters, 1991). While it is true that advanced search options allow for better search results, they also require a better understanding of the search process and more in-depth training. Other factors related to interface design, which might have been considered as influencing the choice of the basic search, can be 
Understanding of OPAC terminology

(424 responses)

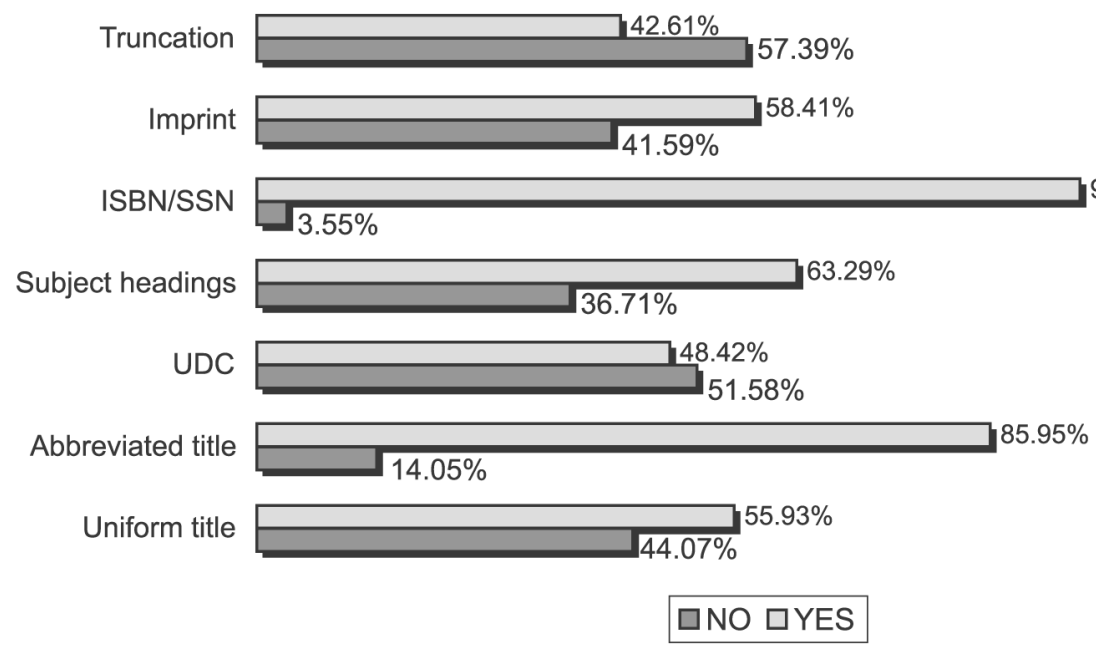

\section{Search options most frequently used, by type of user} (422 responses)

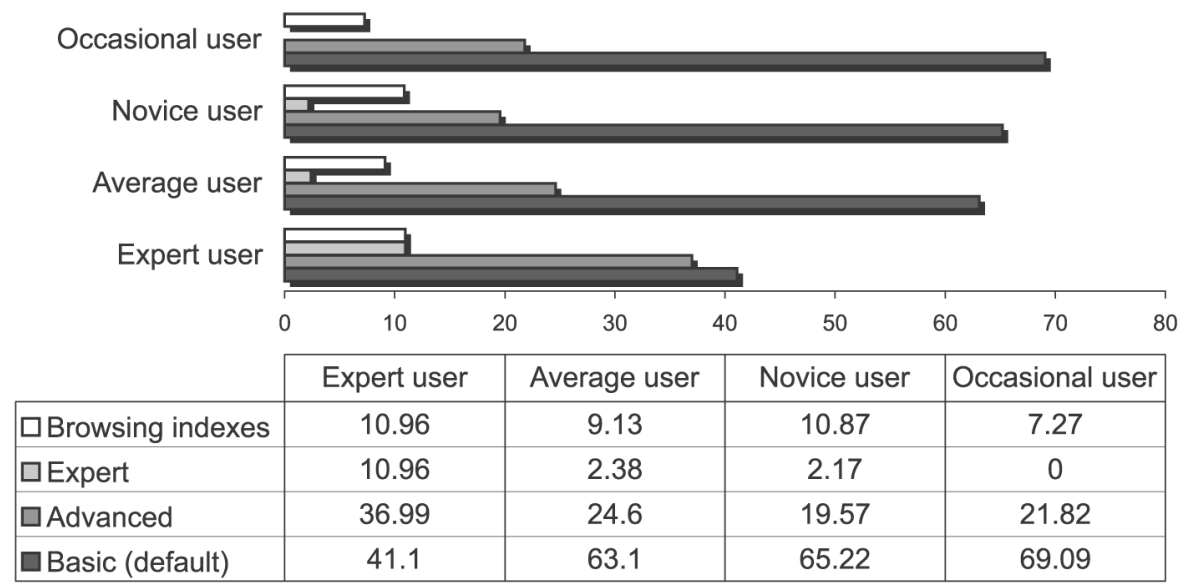

dismissed: 70.83 per cent of users consider that the different options are clearly distinguished and, in addition, a high percentage of users clearly understand the differences between choosing one or another of the search options.

As to the ease of use of certain search options, users approve of Boolean operators and combined field searches (also using Boolean operators). However, these results should be studied with caution since several works have described difficulties that

\section{Using the OPAC}

199

Figure 9. Understanding of OPAC terminology

Figure 10. Figure10. Search options most frequently used, by type of user 
EL

24,2

200 users have in applying Boolean logic successfully, particularly in that they assign values to the AND / OR operators that are contrary to their actual meaning (Larson, 1992; Borgman, 1996). For example, simple logic might lead a searcher to assume that AND signifies a broad search as opposed to OR, that suggests restriction. As such, Boolean logic cannot be considered intuitive for the end user and it requires some practice in order to reach a certain level of proficiency. Also, it should be remembered that the terms employed by the user must coincide with the contents of the bibliographic records in order to have a successful search.

A more detailed analysis of this appraisal can be seen in Figure 11. The highest values are found in all cases in the "Average" category, followed by "Good". It is interesting to note that the highest percentage of "Poor" or "Bad" is found with the Universal Decimal Classification (UDC). Users find the use of truncation difficult, even though this is likely due to the fact that a significant proportion (57.39 per cent) of persons participating in the evaluation are unaware of the meaning of this term and it is quite probable that they do not understand its function. Users consider the use of subject headings in the search to be easy although it should be recognized that keyword searching greatly facilitates retrieval from this field. User approval declines when judging the ease of use of the UDC. A factor that could contribute to this drop in approval is the inability of the system to retrieve symbols used in the UDC, such as full stops or commas.

The fields most heavily used for searching are author and title, used in 87.59 per cent and 88.78 per cent of the cases respectively. Subject searches are used by 45.82 per cent of the users, with decreasing use of searches on ISBN/ISSN, series, UDC, and record number. This data coincides with the results obtained by Larson (1991b) who, in using transactional analysis, discovered a progressive decline over six years in the use of subject heading searches. This coincided with a considerable increase in searching on keywords in the title field. Regarding other options, such as searching on words and

Ease of use of ...

\begin{tabular}{l} 
Combined field search \\
Subject headings \\
Truncation \\
Boolean operators \\
\cline { 2 - 6 } \\
\cline { 2 - 6 } \\
\cline { 2 - 6 }
\end{tabular}

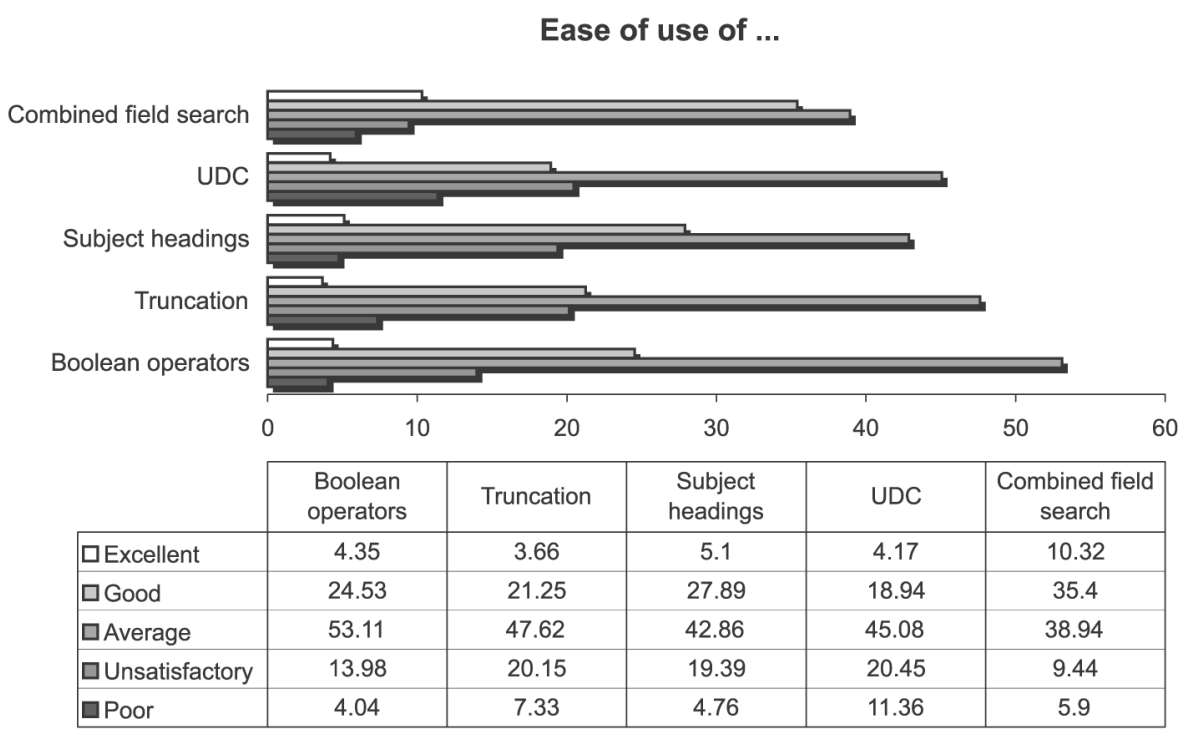

Figure 11.

Ease of use of ... 
phrases (available independently of the search option chosen), the majority of users say that they understand the difference between word and phrase searching; only 17.73 per cent admit to not knowing the difference. Something similar happens with index searching on different fields. As can be seen in Figure 12, the majority of persons answering this question state that they know the difference, although the percentage decreased for series searching which could reflect a lack of user familiarity with the specific terminology.

As was noted above, the user tends to make less use of the more sophisticated search options. A more detailed analysis of the advanced search (Figure 13) clearly illustrates that users do not understand the function - or even the meaning - of many of the options that are available through this option. Thus, 85.33 per cent do not understand the utility of the search on "Other codes" (classification systems other than

\section{Fields most frequently used in searching (419 responses)}

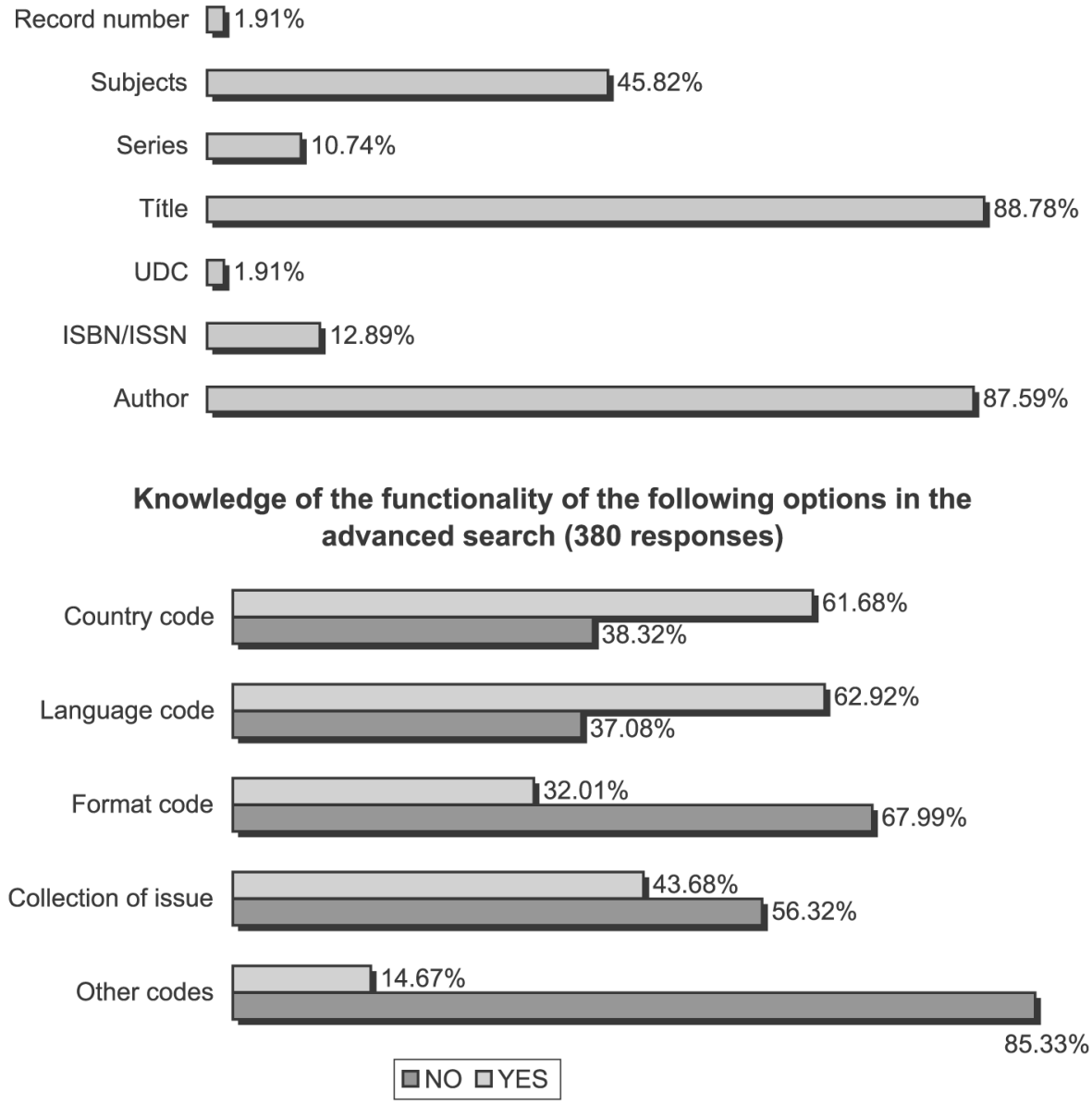

\section{Using the OPAC}

201
Figure 12 . Fields most frequently used in searching
Figure 13. Options for advanced searching 
EL

24,2

202 the UDC that a library might use locally); 67.99 per cent do not understand the function of "Format code" (books, journals, maps, etc.), and 53.32 per cent do not understand the functionality of searching by series or issue collection (names of collections created in different libraries of the Network.)

\section{Information retrieval by subject}

In retrieving information by subjects, OPAC users must overcome both mechanical and conceptual problems (Borgman, 1986). In most cases the help system is not effective in aiding the user to retrieve relevant information using this search option. Current OPACs lack adequate help systems that would allow users to transfer queries formulated into natural language into the controlled language used by the system. Nor do they have mechanisms that would allow users to find alternative forms for carrying on when a search fails.

An important percentage of subject searches do not retrieve any results and are considered failed searches. This is a consequence of one or a combination of the following factors: lack of knowledge of the system of subject headings, orthographic, typographic errors, or both, lack of understanding of Boolean logic, and absence of cross references ("use" and "see also") (Larson, 1992).

Large and Beheshti (1997) noted that in information retrieval by subject, users have to conceptualize their information needs by means of a subject that must be expressed in specific terms. At the same time these terms must coincide with those used in the system. In addition, they must know how to redefine their information needs in cases where too many or no results are retrieved and also how to recognize when the search has ended because it has retrieved all possible results. Some studies have shown (Borgman, 1986; Larson, 1992) that the main difficulties in subject searching are related to the lack of understanding on the user's part of the semantic and syntactic structures, Boolean operators, controlled vocabularies, and other tools such as subject headings. It is due precisely to these difficulties that users opt for keyword searching in the title or subject fields, or anywhere else in the record.

CSIC users are no exception since the preferred option for subject terms is through keywords in the title field, used by 75.31 per cent of users. A lower percentage use keywords in the subject field. Both search options allow users to avoid the complexity of using controlled language and obviously do not require them to understand its structure (subject headings list of the CSIC Library Network). Still the use of subject indexes is low, considering the fact that users are not unhappy with the search results obtained from subject heading searches.

Although this type of search is employed less often, 48.06 per cent of the users that employ index searching consider the results obtained from subject term searches to be appropriate, 33.87 per cent consider them to be too generic, 3.87 per cent feel that they are too specific, and only 3.55 per cent consider them as not appropriate at all. No significant differences are found by area or by experience in the use of the catalogue (Figure 14).

\section{Failed searches and information overload}

Failed searches and information overload are two classic problems, well defined by Larson (1991a) and encountered - to a greater or lesser degree - by any OPAC user. A significant percentage of users, 32.48 per cent and 36.57 per cent, frequently obtain few 
Figure 14. Appraisal of results using subject indexes

or no results to their search. Nevertheless, 60 per cent say that they have no problems in increasing the results of their search if too few have been retrieved (Figure 15).

According to the users, the basic cause for the lack of results (too few or none) is the absence of records coinciding with the information request (41.52 per cent). The lack of experience in using the catalogue (17.65 per cent) and errors in personal names (16.61 per cent) are also considered as major causes of failed searches - individually or together - with other factors such as the use of characters unrecognized by the system, typographical errors, or lack of understanding of correct use of subject searching. (Figure 16)

Some 60 per cent of users claim to have no difficulty in expanding the search results when an insufficient number of records are retrieved. As shown in Figure 17, the most frequently used method is to repeat the search with less precision (51.77 per cent). Fewer (22.34 per cent) employ related terms and others (21.28 per cent) turn to indexes

\section{Users obtaining too few, or no, results (396 responses)}
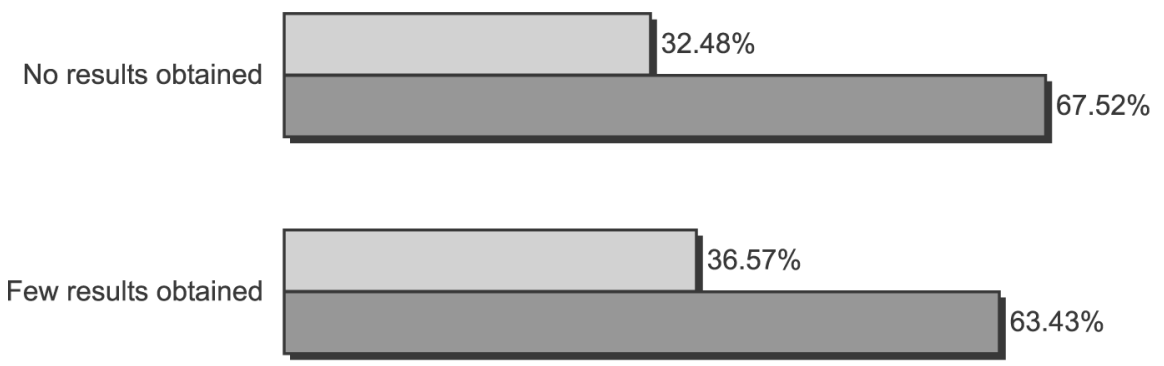

Figure 15. Users obtaining too few, or no, results 
EL

24,2

204

Figure 16.

Causes of system results with no hits
Figure 17.

Methods for expanding search results

\section{Causes for the system returning no results (289 responses)}

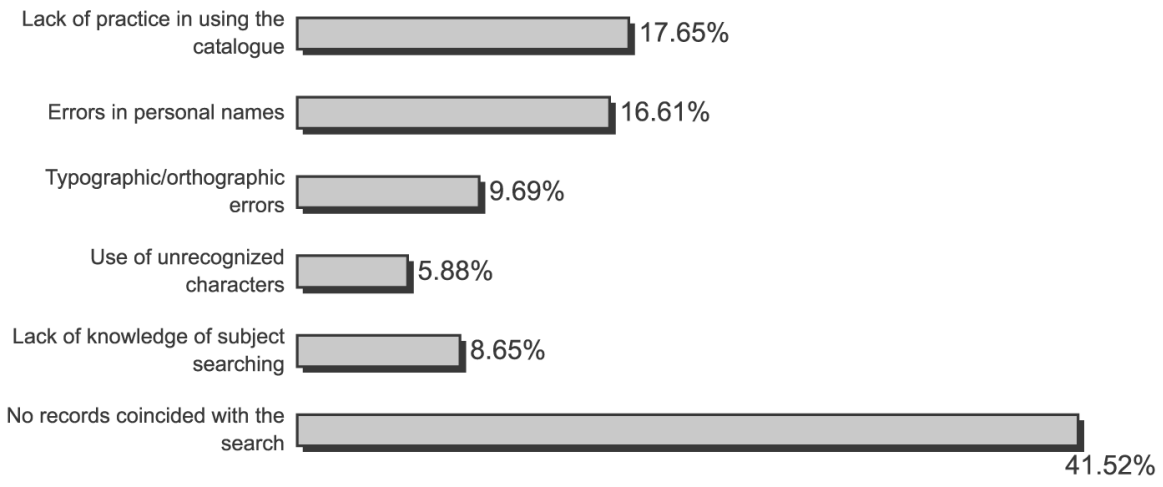

Methods for expanding search results

(282 responses)

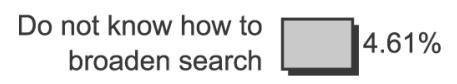

Attempt to be less precise

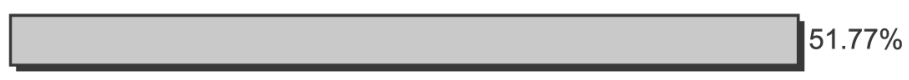

General terms $21.28 \%$

Related terms $22.34 \%$

to find more generic terms. Only 4.61 per cent of those persons answering this question do not know how to expand the results.

Information overload is frequently related to the size of the database though other factors also intervene, such as the use of key words and truncation or the tendency of users to employ highly generic words in their searches. In this study 35.81 per cent of users frequently obtain too many results and, contrary to what happens by expanding a search, 25.24 per cent admit to having problems in reducing the number of results (Figure 18).

An important percentage of users answering this question (42.08 per cent) formulate the search a second time and introduce more words in the query form in order to reduce the number of results; 23.76 per cent limit by year, and 12.38 per cent modify the Boolean operators in the search strategy. Another 14.76 per cent use the first and second method indistinctly, while 5.24 per cent prefer introducing more terms or 
Users obtaining too many results

(300 responses)

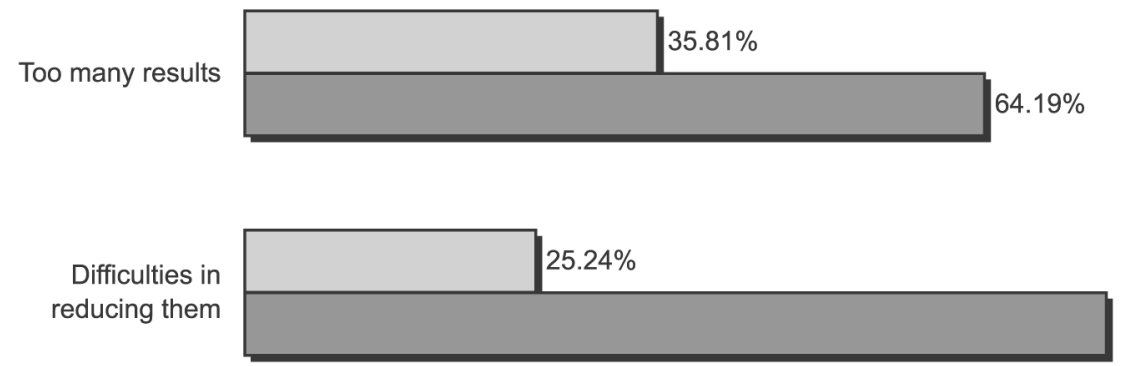

$74.76 \%$

QNO DYES

\section{Using the OPAC}

205

Figure 18.

Users obtaining too many

results

modifying the operators. These methods are used indistinctively by users that admit to having problems in reducing the number of records retrieved as well as by those with no apparent difficulty (Figure 19).

Information overload is made all the worse in many cases by the absence of a mechanism for sorting results according to relevance criteria or appropriateness and by the incomplete information provided in bibliographic records. If it were more complete, users could evaluate more adequately the documents retrieved. The result is that in successful searches users are obliged to examine long lists of documents, with the inherent risk that they might be tempted to abandon this task before having reviewed them all. The saturation point or the maximum number of records that an OPAC user is willing to examine depends, among other factors, on the objective of, and motivation for, the search. In the case of CSIC's OPAC users, the point of saturation is

\section{Methods for reducing search results (404 responses)}

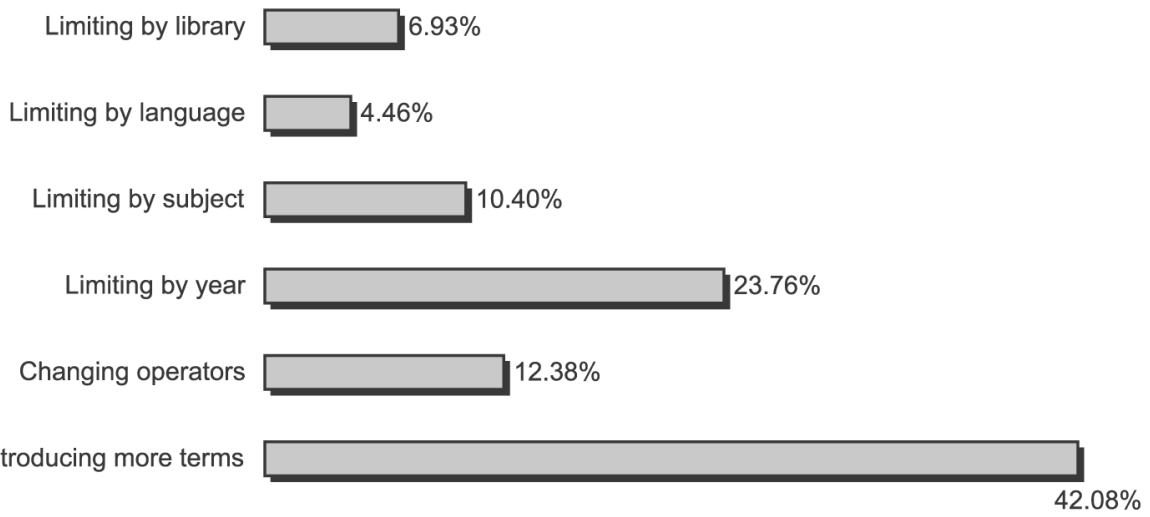

Figure 19. Methods for reducing search results 
EL

24,2

206

fixed at around 73.8, meaning that the average number of screens that will be viewed before giving up on the results is 7 (by default each screen shows an abbreviated list of 10 records.) This number, 73.8, represents a very high saturation rate if compared to the 9.1 documents that the typical user of the MELVYL system examined before ending the search, as revealed in a transaction log analysis (Larson, 1986). In terms of the causes leading CSIC's OPAC users to abandon the system, information overload cannot be considered relevant since it only occurs in 0.25 per cent of the cases. More than half of the users answering this question -55.91 per cent- only give up on the search when they have obtained the needed information as opposed to 38.11 per cent who decide to quit the search if they obtain no results and do not understand the reasons for the failed search.

\section{Presentation of the results}

A high percentage of users answering this question (92.12 per cent) consider that the records can be viewed clearly on the screen. The meaning of some of the tags used for visualizing the records is not always clear: significantly, 61.89 per cent of the users do not understand "Aut.Congr" (Conference as main author), 56.85 per cent do not understand "Sec.Autor" (Secondary author), and 75 per cent do not understand "Sec.Entidad" (Secondary entity). Unsurprisingly, the searchers that admit to knowing the meanings of these terms tend to consider themselves as expert users (Figure 20).

Non-linear access to information, made possible by hypertext, is especially significant in OPACs since the use of these links greatly enriches information access. OPACs offer the opportunity to access different documents related among themselves by common factors, such as author, title, subject, or the classification number. In spite of the undeniable usefulness of hypertext as a way of providing multidimensional access to information, these links are purely superficial since OPACs were not conceived as true hypertext environments. They still maintain structures based on original formats (MARC) and thus hinder the development of new structures based completely on nodes and links (Ortiz-Repiso and Moscoso, 1999).

More than half of the persons responding to this question (53.55 per cent) do not use hyperlinks, as opposed to 46.54 per cent that do use them. The low use of the

\section{Clarity of tags (399 responses)}

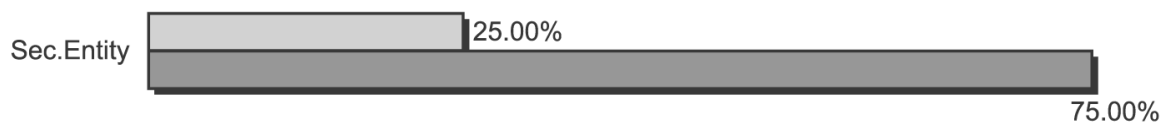

Sec.Author

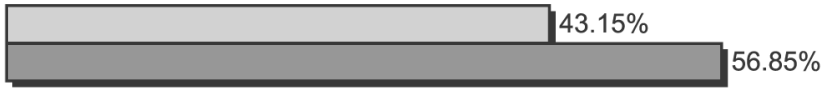

Auth.Conf.

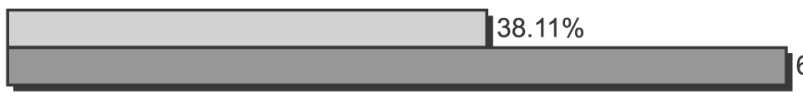

$61.89 \%$

Figure 20.

Clarity of tags $\square$ NO $\square$ YES 
catalogue's hyperlinks is quite surprising. These are useful not only for interconnecting documents (analytical cataloguing) but also for linking to full text e-journals or to images and full text in the case of the Archive catalogue. A very high percentage of the persons answering this question value hyperlinks very positively even though some of them do not make use of them.

\section{Document access}

The most highly considered service for document access in the OPAC is for accessing e-journals, with a total score of between "good" and "excellent" given by 75.07 per cent and with an average score of 4.04. The rest of the services attain average scores: interlibrary loan requests (3.73) and reserve requests (3.52). In spite of an overall adequate scoring, it should be noted that the option of requesting photocopies via the OPAC is considered inadequate by 6.47 per cent of users answering this question. However, on considering the comments submitted, the complaints with this service probably have more to do with how the libraries' reprography services work, rather than with the process of requesting the copies through the OPAC (Figure 21).

\section{Conclusion}

The online catalogue is widely used by CSIC users. The user profile is that of a researcher in the area of sciences accustomed to meeting his/her own information needs via the electronic environment as evidenced by a regular use of a variety of information retrieval tools: OPACs, databases, e-journal platforms, and internet searching tools. Most consider themselves to be average users and they carry out their searches mainly from their place of work, with only a very small percentage going to the library for this purpose.

\section{Appraisal of options for document access (339 responses)}

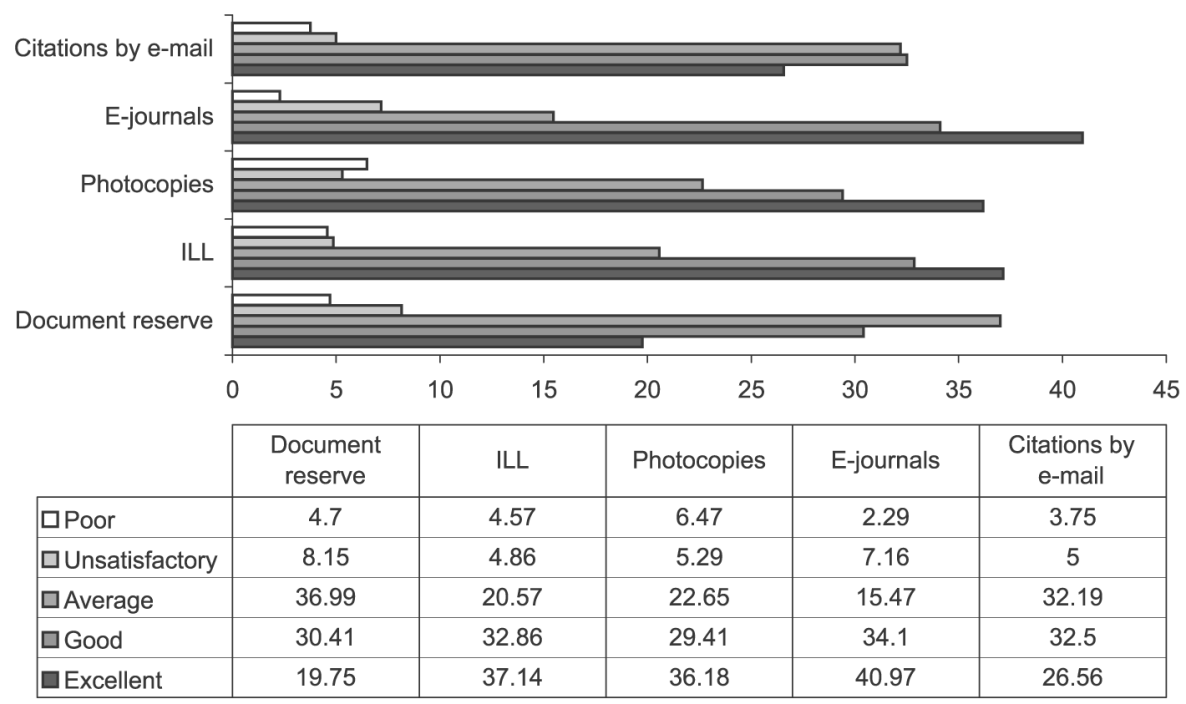

\section{Using the OPAC}

207 
EL

24,2

208
The profile of the "non-user" - a person knowing that the OPAC exists but not making use of it - is a researcher in the area of Biology and Medicine who obtains all needed information from the library's reference service or who claims not to need the OPAC for work, even though - as might be expected - a high percentage of them regularly use specialized databases and e-journal platforms subscribed to by CSIC's Library Network.

The catalogue is not used solely for searching for printed material since a high percentage of the most sought after materials are digital journals. The OPAC serves as an entry point to the electronic journal and, in fact, this feature is among the most highly valued. It is worth noting that CSIC's OPAC users, as revealed through the comments received, request greater clarity regarding the conditions for accessing this type of material. As such, the catalogue should not be merely a simple gateway but rather a source of truly useful information for accessing the material subscribed to by the library. The idea proposed by Peters (1991) of converting the OPAC into something more than a library catalogue has re-emerged, 14 years later, and is on the verge of becoming reality. The installation of a link server for managing access to the digital collection significantly improves the information provided about availability and coverage of access, thus allowing the OPAC to become further integrated into the broader information universe.

The majority of respondents describe themselves as satisfied or somewhat satisfied with the catalogue in general terms. Nevertheless, as is the case of information retrieval on the Web, intuition appears to be the method most widely employed by users searching the OPAC. The help offered online or by the librarian is seldom used. The catalogue is used, therefore, at a very simple level and the more advanced features of the system are virtually unknown. This should make the library community reflect upon the importance of developing more intuitive user interfaces and of implementing more useful aids that would allow the user to understand the overall search process.

Regarding users' search habits, it is noteworthy that no significant differences were found with the results of other studies that took place in the 1990s: decrease in the number of subject searches and preference for author and title field searches. A significant percentage of users frequently obtain few results or no results at all, from their searches. While expanding the number of results is not difficult for users, limiting the results of a search that has retrieved too many hits does appear to be a problem.

Information overload is frequently heightened due to the absence of mechanisms for sorting the results according to relevance criteria or appropriateness and to the lack of fuller bibliographic information on the records that would allow the user to judge more adequately the retrieved documents. Thus, in successful searches users are forced to examine long lists of documents, frequently causing them to give up before having reviewed the entire batch of results. The OPAC user is a patient user, willing to analyze on average seven screens of results and many of them only finalize the search when they have obtained the needed information. Nonetheless, more than a third of them decide to give up the effort when the search produces no results and they do not understand the reason for it.

The OPAC continues to be a highly used search tool by researchers. Nevertheless, catalogues developed in a web environment must find a way to implement more efficient search mechanisms than those based on Boolean operators and exact hits. These traditional approaches frequently prevent users from obtaining precise search 
results. The introduction of feedback systems and of result displays arranged according to relevance or in clusters, as are currently provided by the more advanced internet search engines, would undoubtedly be very well received.

As noted by Novotny (2004) if the appearance of OPACs continues changing and improving without a corresponding change in functionality, it is likely that within two decades studies will still be analyzing why online catalogues continue to be difficult to use, on the whole, by the end user. Today, users' expectations are based on the fast and easy access to information found on the internet where many commercial services and free resources can satisfy their information needs as soon as they are formulated (Davidson, 1999). Against this backdrop, one can assume that the relevance of OPACs will decline as compared to other resources and that the reason that they still continue to be used is mainly for locating print documents. However, in spite of the tough competition from the ease and immediacy of information access on the internet and from the encroachment of more powerful search capabilities such as federated searching or citation linking - frequently to databases managed or contracted by the library - the OPAC continues to be an essential tool for providing access to quality information. Such information can be in paper or in electronic format and available by accessing e-journals, bibliographic databases, and other resources selected and evaluated by the library itself. It is now necessary for the OPAC to insert itself into, and interact with, a much broader universe of information.

\section{Notes}

1. www.csic.es/cbic/cbic.htm

2. http://aleph.csic.es

\section{References}

Borgman, C.L. (1986), "Why are online catalogs hard to use? Lessons learned from information retrieval studies", Journal of the American Society for Information Science, Vol. 37 No. 6, pp. 387-400.

Borgman, C.L. (1996), "Why are online catalogs still hard to use?", Journal of the American Society for Information Science, Vol. 47 No. 7, pp. 493-503.

Cochrane, P.A. and Markey, K. (1983), "Catalog use studies: since the introduction of online interactive catalogs: impact on design for subject access", Library and Information Science Research, Vol. 5 No. 4, pp. 337-63.

Davidson, L.A. (1999), "Libraries and their OPACs lose out to the competition", Library Computing, Vol. 18 No. 4, pp. 279-83.

Delsey, T. (2001), "The Library Catalogue in a Network Environment", Proceedings of the Bicentennial Conference on Bibliographic Control for the New Millenium, Library of Congress, Washington, DC.

Halcoussis, D., Halverson, A.L., Lowenberg, A.D. and Lowenberg, S. (2002), "An empirical analysis of web catalog user experiences”, Information Technology and Libraries, Vol. 21 No. 4, pp. 148-57.

Hildreth, C.R. (1985), "Online public access catalog”, in Williams, M.E. (Ed.), Annual Review of Information Science and Technology (ARIST), Vol. 20, Knowledge Industrial, New York, NY, pp. 232-85. 
EL

24,2
Hildreth, C.R. (2001), "Accounting for users inflated assessments of on-line catalogue search performance and usefulness: an experimental study", Information Research, Vol. 6, available at: http://informationr.net/ir/6-2/paper101.html

Hunter, R.N. (1991), "Successes and failures of patrons searching the online catalog at a large academic library: a transaction log analysis", $R Q$, Vol. 30 No. 4, pp. 395-402.

Large, A. and Beheshti, J. (1997), "OPAC's: a research review”, Library \& Information Science Research, Vol. 19 No. 2, pp. 111-33.

Larson, R. (1986), Workload Characteristics and Computer System Utilization in Online Library Catalogs, University of California, Berkeley, CA.

Larson, R. (1991a), "Between scylla and charybdis: subject searching in the online catalog", in Godden, I. (Ed.), Advances in Librarianship, Academic Press, San Diego, CA, pp. 175-236.

Larson, R. (1991b), "The decline of subject searching: Long-term trends and patterns of index use in online catalog", Journal of the American Society for Information Science, Vol. 42 No. 1, pp. 93-104.

Larson, R. (1992), "Evaluating of advanced retrieval techniques in a experimental online catalog", Journal of the American Society for Information Science, Vol. 43 No. 1, pp. 34-53.

Novotny, E. (2004), "I don't think I click: a protocol analysis study of use of a library online catalog in the Internet age", College \& Research Libraries, Vol. 65, pp. 527-37.

Ortiz-Repiso, V. and Moscoso, P. (1999), "Web-based OPACs: Between tradition and innovation”, Information Technology and Libraries, Vol. 18 No. 2, pp. 68-77.

Peters, T.A. (1991), The Online Catalog: A Critical Examination of Public Use, McFarland \& Company, Jefferson, NC.

Schwartz, J. (2002), "Internet access and end-user needs: computer use in an academic library", Reference and User Services Quarterly, Vol. 41 No. 3, pp. 253-62.

Webster, P. (2004), "Metasearching in an academic environment”, Online, Vol. 28 No. 2, pp. 20-3.

$\mathrm{Yu}, \mathrm{H}$. and Young, M. (2004), "The impact of web search engines on subject searching in OPAC", Information Technology and Libraries, Vol. 23 No. 4, pp. 168-80.

\section{Further reading}

Fernández Molina, J.C. and Moya, F. (1998), "Los catálogos de acceso público en línea: El futuro de la recuperación de información”, Asociación Andaluza de Bibliotecarios, Málaga.

\section{About the authors}

Virginia Ortiz-Repiso has been Professor of the Department of Library and Information Science, University Carlos III of Madrid (Spain) since 1991. She has a PhD in Information Science and is a specialist in automated catalogs, information retrieval and management of technological resources in information services. She has published many articles devoted to these issues and also has participated in several national projects on the application of IT to libraries. Virginia Ortiz-Repiso is the corresponding author and can be contacted at: virginia@bib.uc3m.es

Virginia Bazán has a BA in History and a B.A. in Library and Information Science from the University of Alcalá (Madrid). She worked as a documentation officer for the Defense Ministry (Spain), Spanish Council for Scientific Research (CSIC), and has collaborated as a professor with different educational institutions, among them the University Carlos III of Madrid. At the present time she carries out her professional activities at the Audio-visual Archive of the main Spanish public television broadcaster, TVE.

Agnès Ponsati has a degree in Spanish Philology and Linguistics and a Master's degree in Librarianship from the University of Barcelona (1986). Currently she is director of the Library 
Coordination Unit at the Spanish Council for Scientific Research (CSIC). Previously she had worked at the Technical Department of the University of Barcelona's Library (1987-1990) and as automation manager at the Catalonian branch of CSIC libraries (1990-1993). She is a specialist in automated union catalogs in distributed networks and in management and coordination of library services and collections in hybrid-digital research libraries. She has published many articles devoted to these issues and also has participated in several national and European projects on the application of IT to scientific libraries.

Mario Cottereau has a degree in Geography and History (Universidad Autónoma de Madrid, Spain) and a Master of Librarianship (Centro de Estudios Bibliográficos y Documentarios, National Library, Spain). Since 2001 he has been Head of the Professional Coordination Service of the Library Coordination Unit of the Spanish Council for Scientific Research (CSIC) in Madrid. Main responsibilities include: technical process (cataloging and classification, standards, MARC Format, etc.), authority control, librarian education and archives automation. He has taken part in research projects promoted by CSIC's Library Coordination Unit and has participated with many papers and communications in professional librarianship congresses.

\section{Using the OPAC}

211

To purchase reprints of this article please e-mail: reprints@emeraldinsight.com Or visit our web site for further details: www.emeraldinsight.com/reprints 